\title{
ETNOZOOLOGI SEBAGAI MISTIS OLEH MASYARAKAT DAYAK SIMPAKNG DI DESA SEMANDANG KANAN KECAMATAN SIMPANG DUA KABUPATEN KETAPANG
}

\author{
(Etnozoologi As Mystical By Dayak Simpakng Community In The Semandang Kanan Village, \\ Simpang Dua District Ketapang)
}

\section{Frengky Bagas Persada, Muhammad Sofwan Anwari, Ahmad Yani}

Fakultas Kehutanan Universitas Tanjungpura Pontianak, Jl. Daya Nasional Pontianak 78124

Email: frengkybagas@gmail.com

\begin{abstract}
Dayak Simpakng community, which is located in Semandang Kanan Village, Simpang Dua District, Ketapang Regency, is a Dayak community that still preserves ancestral culture for generations. One of their cultures is still utilizing the animals around them as mystical. The purpose of this study is to obtain data of animals species that are used as mystics, the parts used and the meaning of these animals. The method used in this study is a survey method, the selection of respondents was carried out using snowball sampling techniques. Based on the results of interviews with 25 selected respondents obtained 23 species of animals from 19 families which used as a mystic by the Dayak Simpakng community. Some parts that are used as mystical that is the sound, foot in animals and all the body.
\end{abstract}

Keywords: Dayak Simpakng, Ethnozoology, Mystical Animal.

\section{PENDAHULUAN}

Kalimantan merupakan pulau di Indonesia yang memiliki tingkat keanekaragaman hayati yang sangat tinggi, flora dan faunanya masih dapat kita temui di dalam hutan Kalimantan. Pemanfaatan hewan dan tumbuhan telah dilakukan oleh berbagai etnis yang ada di Kalimantan sejak dulu untuk memenuhi kebutuhan hidupnya, antara lain sebagai sumber bahan makanan, obat-obatan, sarana ritual kebudayaan dan kepentingan ekonomi subsisten. Ragam pemanfaatan hewan merupakan implikasi dari beragamnya etnis, baik dalam hal jenis hewan yang dimanfaatkan, bentuk pemanfaatan maupun cara memanfaatkannya (Yogi, 2017).

Menurut Eprilurahman $d k k$. (2012) hewan juga digunakan untuk upacara adat pada pesta-pesta besar seperti upacara pernikahan adat dan bhatara/berdukun hewan yang digunakan ayam kampung (Gallus gallus domesticus) dan babi (Sus barbatus). Tulang karapaks kura tangkup (Cuora amboinensis) dipercaya oleh sebagian orang memiliki kekuatan magis berkhasiat sebagai obat penyerap racun dan dapat digunakan sebagai sarana untuk mengabulkan atau melancarkan dalam menagih hutang.

Salah satu etnis asli yang terdapat pada Provinsi Kalimantan Barat yaitu Suku Dayak terkenal dengan kearifan lokalnya dari masyarakat setempatnya, hal-hal yang menarik Suku Dayak yaitu ritual-ritualnya. Masyarakat Dayak memang sangat terkenal kental sekali mistisismenya. Setiap ritual dan bahkan aspek kehidupan lainnya selalu diselipi 
dengan kekuatan-kekuatan mistis. Suku Dayak juga memanfaatkan hewan dalam upacara ritual untuk memanggil roh-roh gaib untuk dimintai sesuatu, baik dalam bentuk tanda-tanda maupun petunjuk yang berhubungan dengan kelangsungan dan kebahagiaan manusia serta beberapa jenis hewan menurut kepercayaan Suku Dayak dikatakan mistis karena hewan tersebut membawa pertanda bagi kehidupan mereka (Kumparan, 2017).

Keragaman dalam pemanfaatan satwa mendorong terbentuknya pola yaitu sebuah sistem atau cara kerja yang tetap dalam memanfaatkan berbagai jenis satwa. Hal ini berkaitan erat dengan proses interaksi yang berkembang antara etnis tertentu yang tinggal di sekitar hutan alam dengan lingkungannya dari waktu ke waktu. Interaksi yang kuat tersebut melahirkan cara tersendiri pada komunitas masyarakat dalam memperlakukan sumber daya alam, hubungan antara manusia dengan alam membentuk nilainilai yang arif dan menyatu dalam mengelola alam lingkungan yang akirnya membentuk sebuah tradisi (Li, 1999).

Tradisi adalah segala sesuatu yang berhubungan dengan adat, kepercayaan kebiasaan, upacara dan sebagainya. Tradisi setiap kelompok masyarakat bersifat dinamis, artinya ada pengurangan dan penambahan pada tradisi tersebut sesuai dengan kondisi pola pikir pendukungnya. Bentukbentuk tradisi yang dilakukan oleh berbagai suku bangsa tersebut antara lain perkawinan, pesta adat, kematian dan lain sebagainnya (Augristina, 2014). Masing-masing bentuk upacara tersebut dilakukan dengan cara-cara tertentu yang menjadi ciri khas dari masing-masing suku bangsa salah satunya tradisi dari Masyarakat Suku Dayak. Tradisi atau budaya disatu pihak ada yang masih dipertahankan oleh masyarakat dan tidak mengalami perubahan sama sekali, di pihak lain ada yang mengalami perubahan atau malah hilang sama sekali sebagai tradisi yang menjadi bagian dari masyarakat Suku Dayak.

Masyarakat Suku Dayak Simpakng yang terletak di Desa Semandang Kanan, Kecamatan Simpang Dua Kabupaten Ketapang, merupakan suku Dayak yang masih menjaga budaya leluhur secara turun temurun. Salah satu budaya mereka yaitu masih memanfaatan hewan yang ada disekitarnya sebagai mistis. Informasi dan pengetahuan mengenai pemanfaatan hewan oleh suku Dayak Simpakng belum banyak diketahui, oleh sebab itu diperlukan kajian mengenai etnozoologi sebagai mistis Masyarakat Dayak Simpakng Desa Semandang Kanan.

Tujuan penelitian ini adalah (1) Mendapatkan data jenis-jenis hewan yangdimanfaatkan sebagai hewan mistis atau pertanda oleh Masyarakat Dayak Simpakng, Desa Semandang Kanan, Kecamatan Simpang Dua, Kabupaten Ketapang (2) Mendapatkan data cara pemanfaatan hewan untuk mistis atau pertanda oleh masyarakat Dayak 
Simpakng di Desa Semandang Kanan Kecamatan Simpang Dua Kabupaten Ketapang.

\section{METODE PENELITIAN}

Penelitian ini dilaksanakan di Desa Semandang Kanan Kecamatan Simpang Dua Kabupaten Ketapang pada tanggal 22 Juli 2019 sd 18 agustus 2019 dengan menggunakan metode survey melalui wawancara mendalam (indepth survey) terhadap responden terpilih. Pemilihan responden menggunakan teknik snow ball sampling atau dilakukan secara berantai dengan meminta informasi pada orang yang telah diwawancarai sebelumnya, demikian seterusnya (Poerwandari, 1998). Penelitian ini dilakukan dengan cara pencatatan mengenai keterangan jenis-jenis hewan yang dimanfaatkan masyarakat setempat (responden). Peneliti meminta rekomendasi calon responden dari kepala desa, kepala adat, kepala dusun, dukun, pengguna, orang tua, pemburu, dan lain-lain. Peneliti tidak membatasi jumlah responden maupun objek penelitian. Pengambilan data akan dihentikan apabila peneliti telah merasa data yang terkumpul telah cukup. Hal ini sesuai dengan konsep titik saturasi (saturation point) ketika data yang diperoleh tidak memberikan informasi baru dalam analisis (Parthami, 2009). Pada penelitian ini telah diperoleh responden sebanyak 25 orang. Beberapa bagian yang dimanfaatkan sebagai mistis atau pertanda adalah suara, organ tubuh, hewan yang dengan tiba-tiba masuk ke dalam rumah, dan hewan yang melintasi kampung atau pemukiman warga. Data yang didapat dari hasil wawancara dibuat dalam bentuk tabulasi kemudian dijabarkan secara deskriptif.

HASIL DAN PEMBAHASAN

Jenis Hewan yang Dimanfaatkan sebagai Mistis atau Pertanda oleh Mayarakat Dayak Simpankg

Berdasarkan dari hasil wawancara terdapat 23 jenis hewan yang dimanfaatkan oleh masyarakat Dayak Simpakng sebagai hewan mistis atau pertanda, yang terdiri atas famili Cuculidae, Felidae, Phasianidae, Strigidae, Cicadoidea, Columbidae, Corvidae, Estrildidae, Gekkonidae, Hylobatidae, Lampyridae, Manidae, Mastotermitidae, Monarchidae, Muscicapidae, Nectariniidae, Rallidae, Rollulus dan Turdiae yang termasuk kelas Mamalia, Aves, Reptil dan Insecta. Kelas yang terbanyak dimanfaatkan sebagai hewan pertanda adalah jenis Aves. Beragam jenis pemanfaatan yang digunakan sebagai mistis atau pertanda yaitu suara, organ tubuh, hewan yang dengan tiba-tiba masuk ke dalam rumah dan hewan yang melintasi kampung atau pemukiman warga. Jenis satwa yang dimanfaatkan sebagai mistis atau pertanda disajikan pada tabel 1 . 
Tabel 1. Pemanfaatan Satwa sebagai Mistis oleh Masyarakat Suku Dayak Simpakng di Desa Semandang Kanan Kecamatan Simpang Dua Kabupaten Ketapang (The use of animals as mythic by the Dayak Simpakng people in Semandang Kanan Village, Simpang Dua District, Ketapang Regency)

\begin{tabular}{|c|c|c|c|c|}
\hline No & $\begin{array}{l}\text { Nama } \\
\text { Daerah dan } \\
\text { Nama Indonesia }\end{array}$ & Nama Ilmiah & $\begin{array}{l}\text { Bagian yang } \\
\text { Digunakan }\end{array}$ & Makna \\
\hline 1 & $\begin{array}{l}\text { Kelampio/ } \\
\text { Owa Kelampiau }\end{array}$ & Hylobates muelleri & Suara & $\begin{array}{l}\text { Menandakan waktu Ketika berada } \\
\text { di Dalam hutan. }\end{array}$ \\
\hline 2 & $\begin{array}{l}\text { Bubut/ } \\
\text { Bubut Alang- } \\
\text { Alang }\end{array}$ & Centropus bengalensis & $\begin{array}{l}\text { Suara dan } \\
\text { Seluruh tubuh }\end{array}$ & $\begin{array}{l}\text { Memberi padah atau peringatan akan } \\
\text { terjadi kematian dan Ketika melintasi } \\
\text { atau melewati sebuah kampung }\end{array}$ \\
\hline 3 & $\begin{array}{l}\text { Burung Kak/ } \\
\text { Gagak bangai }\end{array}$ & Corvus enca & $\begin{array}{l}\text { Suara dan } \\
\text { Seluruh tubuh }\end{array}$ & $\begin{array}{l}\text { Memberi padah atau peringatan akan } \\
\text { terjadi kematian dan Ketika melintasi } \\
\text { atau melewati sebuah kampung. }\end{array}$ \\
\hline 4 & $\begin{array}{l}\text { Olang Kuap/ } \\
\text { Burung Hantu }\end{array}$ & Ketupa ketupu & Suara & $\begin{array}{l}\text { Memberi padah atau peringatan akan } \\
\text { terjadi musibah ketika bersuara } \\
\text { disekitar pemukiman warga. }\end{array}$ \\
\hline 5 & $\begin{array}{l}\text { Burung Romak/ } \\
\text { Tali mayat }\end{array}$ & Terpsiphone paradisi & Seluruh tubuh & $\begin{array}{l}\text { Ketika melintasi atau melewati sebuah } \\
\text { kampung, Pertanda buruk, Memberi } \\
\text { tanda-tanda kematian dan musibah. }\end{array}$ \\
\hline 6 & $\begin{array}{l}\text { Kucikng/ } \\
\text { Kucing }\end{array}$ & Felis catus & Suara & Pertanda hadirnya makluk halus. \\
\hline 7 & $\begin{array}{l}\text { Remaokng } \\
\text { /Togung } \\
\text { Macan dahan }\end{array}$ & Neofelis nebulosa & Suara & $\begin{array}{l}\text { Memberi tanda-tanda kematian, } \\
\text { memberi padah atau peringatan agar } \\
\text { tetap berwaspada. }\end{array}$ \\
\hline 8 & $\begin{array}{l}\text { Kuang Kuit/ } \\
\text { Burung Kuang kuit }\end{array}$ & Otus $s p$ & Suara & Pertanda akan terjadi musim buah. \\
\hline 9 & $\begin{array}{l}\text { Pipit/ } \\
\text { Pipit }\end{array}$ & Lonchura fuscans & Seluruh tubuh & $\begin{array}{l}\text { Masuk kedalam Rumah, Memberi } \\
\text { peringatan akan hadirnya kuasa jahat } \\
\text { dan tanda bahwa akan hadirnya makluk } \\
\text { halus, Pertanda buruk. }\end{array}$ \\
\hline 10 & $\begin{array}{l}\text { Sengayan/ } \\
\text { Puyuh Sengayan }\end{array}$ & Rollulus rouloul & Seluruh tubuh & $\begin{array}{l}\text { Masuk kedalam Rumah, } \\
\text { Pertanda akan terjadinya musibah. }\end{array}$ \\
\hline 11 & $\begin{array}{l}\text { Tengiling/ } \\
\text { Terenggiling }\end{array}$ & Manis javanica & Suara & Jelmaan makluk halus. \\
\hline 12 & $\begin{array}{l}\text { Keruak/ } \\
\text { Kareo padi }\end{array}$ & $\begin{array}{l}\text { Amaurornis } \\
\text { phoenicurus }\end{array}$ & Seluruh tubuh & $\begin{array}{l}\text { Masuk kedalam Rumah, } \\
\text { Pertanda buruk }\end{array}$ \\
\hline 13 & $\begin{array}{l}\text { Gagurak/ } \\
\text { Murai batu }\end{array}$ & $\begin{array}{l}\text { Copsychus } \\
\text { malabaricus }\end{array}$ & Seluruh tubuh & $\begin{array}{l}\text { Masuk kedalam Rumah, } \\
\text { Pertanda buruk }\end{array}$ \\
\hline
\end{tabular}


JURNAL HUTAN LESTARI (2020)

Vol. 8 (2) : 396 - 406

\begin{tabular}{|c|c|c|c|c|}
\hline 14 & $\begin{array}{l}\text { Selaseh/ } \\
\text { Burung Kedasih }\end{array}$ & Cacomantis merulinus & Seluruh tubuh & $\begin{array}{l}\text { Masuk kedalam Rumah, } \\
\text { Pertanda buruk. }\end{array}$ \\
\hline 15 & $\begin{array}{l}\text { Monok Perkutut/ } \\
\text { Perkutut }\end{array}$ & Geopelia striata & Seluruh tubuh & $\begin{array}{l}\text { Masuk kedalam Rumah, } \\
\text { Pertanda buruk. }\end{array}$ \\
\hline 16 & $\begin{array}{l}\text { Nca'la/ } \\
\text { Kacer }\end{array}$ & Copshycus saularis & $\begin{array}{l}\text { Suara dan Seluruh } \\
\text { tubuh }\end{array}$ & $\begin{array}{l}\text { Ketika melintasi atau melewati } \\
\text { sebuah kampung, } \\
\text { Memberi peringatan akan } \\
\text { hadirnya kuasa jahat. }\end{array}$ \\
\hline 17 & $\begin{array}{l}\text { Cocap/ } \\
\text { Pijantung kecil }\end{array}$ & $\begin{array}{l}\text { Arachnothera } \\
\text { longirostra }\end{array}$ & Seluruh tubuh & $\begin{array}{l}\text { Masuk kedalam Rumah, } \\
\text { Pertanda buruk. }\end{array}$ \\
\hline 18 & $\begin{array}{l}\text { Manok/ } \\
\text { Ayam }\end{array}$ & Gallus domesticus & Suara & $\begin{array}{l}\text { Pertanda bahwa di sebuah } \\
\text { kampung akan ada wanita } \\
\text { hamil tanpa orang tua atau } \\
\text { ayah, Pertanda pasang laut. }\end{array}$ \\
\hline 19 & $\begin{array}{l}\text { Sempidan/ } \\
\text { Sempidan }\end{array}$ & Lophura bulweri & Kaki Sempidan & $\begin{array}{l}\text { Mengusir makluk halus yang } \\
\text { mengganggu anak-anak atau } \\
\text { bayi }\end{array}$ \\
\hline 20 & $\begin{array}{l}\text { Cocak/ } \\
\text { Cicak }\end{array}$ & $\begin{array}{l}\text { Hemidactylus } \\
\text { platyurus }\end{array}$ & Suara & $\begin{array}{l}\text { Sesuatu yang kita ceritakan } \\
\text { adalah benar adanya }\end{array}$ \\
\hline 21 & $\begin{array}{l}\text { Ngkorop/ } \\
\text { Kunang-kunang }\end{array}$ & Photuris lucicrescens & Seluruh tubuh & $\begin{array}{l}\text { Masuk kedalam Rumah, } \\
\text { Petanda akan mendapat hewan } \\
\text { buruan. }\end{array}$ \\
\hline 22 & $\begin{array}{l}\text { Kriang/ Mpanyat } \\
\text { Tonggeret }\end{array}$ & $\begin{array}{l}\text { Megapomponia } \\
\text { imperatoria }\end{array}$ & Suara & $\begin{array}{l}\text { Memberi tanda-tanda } \\
\text { kematian. }\end{array}$ \\
\hline 23 & $\begin{array}{l}\text { Nakne/ } \\
\text { Anai-Anai }\end{array}$ & Insoptera edenda & Seluruh tubuh & $\begin{array}{l}\text { Masuk kedalam Rumah, } \\
\text { Petanda akan terjadi musim } \\
\text { hujan dan Nyawo Ikan (Ikan } \\
\text { masa bertelur, ikan mudik } \\
\text { keluar dari sarangnya dan } \\
\text { mudah di tangkap) }\end{array}$ \\
\hline
\end{tabular}

Sumber: Data Hasil Wawancara Bersama Responden Terpilih di Desa Semandang Kanan Kecamatan Simpang Dua Kabupaten Ketapang Tahun 2019 (Data of Results of Interviews with Selected Respondents in Semandang Kanan Village, Simpang Dua District, Ketapang Regency in 2019)

Owa kelampiau atau kelampio merupakan primata terkecil dalam keluarga kera memiliki bulu berwarna cokelat atau abu-abu yang menutupi tubuhnya dengan bulu melingkar berwarna terang di bagian wajahnya. Primata ini Aktif di siang hari untuk mencari makanan berupa buah-buahan, mempunyai lengan yang panjang, memiliki berat badan dewasa rata-rata sekitar $5,7 \mathrm{~kg}$ dan mempunyai suara yang panjang dan keras (Payne et al., 2000). Masyarakat Dayak Simpakng sering memanfaatkan suara kelampio 
sebagai penanda waktu ketika berada di dalam hutan, berburu dan beramu mencari bahan bangunan untuk rumah di dalam hutan. Hewan primata ini memiliki suara yang panjang dan keras, masyarakat Dayak Simpakng percaya ketika berada di dalam hutan mendengar suara kelampau berarti menandakan waktu pukul 3-4 subuh, siang hari pukul 11-12, dan sore hari jam 15-15.10 wib. Owa Kelampiau merupakan jenis primata diurnal yang aktif pada pagi hari dan akan beristirahat maksimal 2 jam sebelum petang (Payne et al., 2000). Menurut Manshur et al. (2008) suara yang ditimbulkan oleh owa kelampiau untuk menunjukkan wilayah kekuasaan/teritorinya adalah dengan suara khas yang lama dan keras. Hal ini dikarenakan agar suara tersebut dapat didengar oleh kelompok yang lain dalam radius tertentu. Setiap kelompok owa kelampiau memiliki teritori seluas minimal 20 ha. Owa Kelampiau yang lebih sering mengeluarkan suara (vocal) adalah pejantan. Hal ini karena selain untuk menunjukkan kekuasaannya. Kemampuan vokalisasi dari owa kelampiau jantan juga menentukan persaingan dalam memperebutkan betina (Payne et al., 2000).

Burung Romak atau tali mayat merupakan burung berekor panjang dan berwarna putih, burung ini berukuran 22 cm dengan warna bulu cuilan kepala hitam disertai jambul yang mencolok. Burung jantan mempunyai sepasang bulu ekor tengah yang memanjang hingga $25 \mathrm{~cm}$, melebihi bulu ekor lainnya. Bulu burung betina berwarna coklat-merah bata dengan kepala mengkilap, iris coklat, kulit tanpa bulu di sekitar mata biru, paruh biru berujung hitam dan kaki berwarna biru (National geographic, 2015). Menurut situs kepercayaan masyarakat Dayak Simpakng sekayok, burung romak dianggap mistis atau pertanda di karenakan burung ini sangat jarang ditemui, langka dan dapat memberikan padah atau peringatan agar tetap berwaspada. Masyarakat Dayak Simpakng percaya ketika burung romak, burung bubut, burung Ncala dan burung kak bersuara melintasi atau melewati kampung pemukiman warga, dapat dipastikan di dalam kampung tersebut akan terjadi musibah dan kematian. 


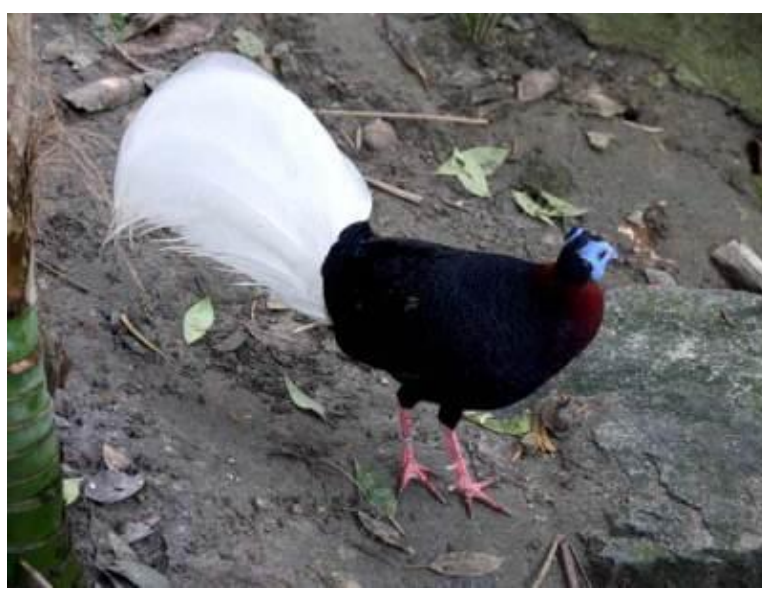

a

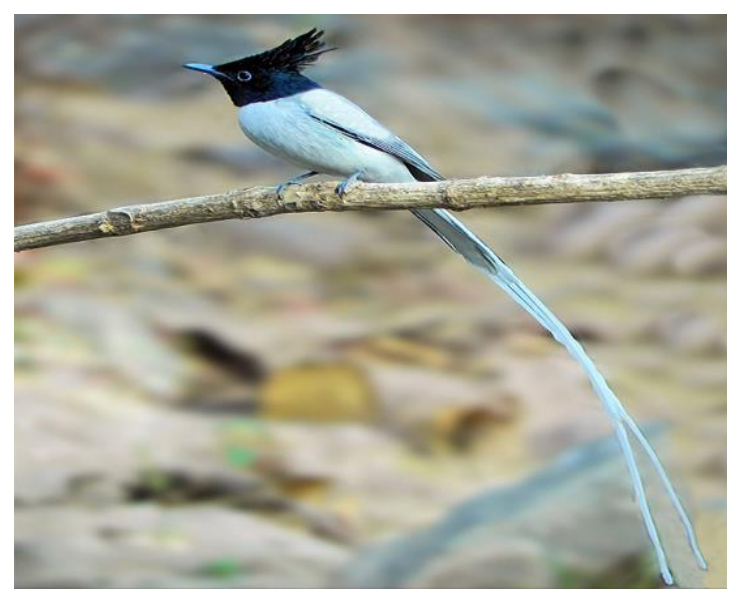

b

Gambar 1: Hewan Mistis; a. Sempidan (Sumber: avise-birds.bio.uci.edu); b. Burung Tali mayat (Sumber: Atharva Amdekar). Mystical animal; a. Sempidan (Source: avisebirds.bio.uci.edu) b. Burung Tali mayat (Source: Atharva Amdekar).

Burung pipit, pijantung kecil, perkutut, murai batu, kareo padi, burung kedasih dan puyuh sengayan diyakini oleh masyarakat Dayak Simpakng dapat memberikan pesan peringatan, pertanda buruk, jika burung-burung ini memasuki rumah pemukiman warga pada malam hari. Rumah yang telah dimasuki oleh burung-burung ini harus di lakukan ritual pembersihan dan tinggalkan atau dikosongkan selama 3 hari. Tujuannya adalah agar terhindar dari musibah dan gangguan-gangguan roh jahat.

Sempidan adalah burung dari Asia Tenggara dalam keluarga Phasianidae, endemik hutan rimba pulau Kalimantan. Burung ini memiliki ciri-ciri dimorfisme seksual, jantannya memiliki total panjang sekitar 80 sentimeter, dan berbulu hitam dengan dada merah marun, kaki merah, ekor panjang putih murni, bulu melengkung, dan kulit wajah biru cerah dengan dua pial yang menyembunyikan sisi-sisi kepalanya. Betina memiliki total panjang sekitar 55 sentimeter, dan keseluruhannya berwarna coklat kusam dengan kaki merah dan kulit muka biru (Roach, 2005). Sempidan dimanfaatkan sebagai hewan mistis oleh mayarakat Dayak Simpakng, kaki dari hewan ini dapat mengusir roh halus yang mengganggu bayi dan anak-anak yang menangis dan susah tidur pada malam hari. Cara memanfaatkan kaki dari hewan sempidan ini untuk mengusir roh halus dengan cara nempama (dibaca mantra pengusir roh halus), kemudian bakar sedikit potongan kaki sempidannya sekitar jam 17.00 sore atau sebelum tidur di area kamar bayi atau anak-anak.

Togung/Remaong atau macan dahan adalah sejenis kucing berukuran sedang, dengan panjang tubuh mencapai $95 \mathrm{~cm}$. Jenis ini pada umumnya memiliki bulu berwarna kelabu kecoklatan dengan gambaran seperti awan dan bintik hitam ditubuhnya. Bintik hitam dikepalanya berukuran lebih kecil dan terdapat totol putih di belakang telinga. Macan dahan mempunyai kaki pendek dengan telapak kaki besar serta ekor panjang dengan garis dan bintik hitam (Sanderson et al., 2008). 
Togung/remaong atau macan dahan memiliki nilai mistis bahkan dianggap sebagai jelmaan roh nenek moyang, salah satu responden mengatakan bahwa hewan ini sudah sangat langka dan jarang ditemui, hanya orang-orang tertentu seperti dukun dan yang masih garis keturunan saja yang dapat melihat hewan ini. Jika hewan ini berbunyi atau mengeluarkan suara pada malam hari maka akan terjadi kematian dan sebagai pesan atau padah peringatan agar berwaspada. Togung/Remaong dipercaya sebagai hewan pelindung masyarakat Dayak Simpakng. Menurut cerita di masyarakat Togung/Remaong ini memiliki tujuh saudara, tiga diantaranya memiliki jiwa yang baik, dan empat lainnya memiliki jiwa yang ganas atau jahat. Pemanggilan remaong pada saat situasi perkampungan dalam keadaan masalah besar, seperti adanya isu-isu peperangan.

Kunang-kunang atau ngkorop adalah sejenis serangga yang dapat mengeluarkan cahaya yang jelas terlihat saat malam hari. Cahaya ini dihasilkan oleh "sinar dingin" yang tidak mengandung ultraviolet maupun sinar inframerah dan memiliki panjang gelombang 510 sampai 670 nanometer, dengan warna merah pucat, kuning, atau hijau, dengan efisiensi sinar sampai 96\% (National geographic, 2015). Ngkorop atau kunang-kunang ini dimanfaatkan oleh masyarakat Dayak Simpakng sebagai pertanda, masyarakat meyakini bahwa ngkorop merupakan jelmaan atau roh hewan di dalam hutan. Hewan ini masuk ke dalam rumah pada malam hari, ngkorop ini harus dibunuh tujuannya adalah agar penjerat atau perangkap hewan yang kita buat di dalam hutan mendapatkan hasil buruan. Kepercayaan dalam membunuh kunangkunang ini sudah dilakukan dari zaman nenek moyang dan terus dilakukan sampai sekarang.

Ayam sering dihubungkan dengan pertanda, masyarakat Dayak Simpakng meyakini bahwa ketika ayam berkokok sebanyak empat kali sebelum subuh di area perkampungan atau permukiman warga menandakan adanya wanita ngampakng atau wanita muda yang akan hamil tanpa suami. Ayam juga dipercaya membawa pertanda ketika berkokok jam 10 malam, menandakan pasang air laut atau air sungai naik ke permukaan.

Cicak merupakan hewan bertubuh pipih lebar, berekor lebar dengan jumbaijumbai halus di tepinya, adanya lipatan kulit agak lebar di sisi perut dan di belakang kaki serta dapat kita temui di dalam rumah (National geographic, 2015). Salah satu responden mengatakan bahwa cicak dimanfaatkan sebagai pertanda saat melakukan hukum adat atau beradat menginterogasi seseorang yang bersalah dan tidak mau mengakui kesalahannya, jika hewan ini berbunyi/bersuara menandakan bahwa sesuatu yang diucapkan benar adanya.

Anai-Anai atau Nakne merupakan salah satu jenis serangga yang keluar pada awal musim hujan, ciri fisiknya sedikit menyerupai semut dengan tubuh yang lebih lunak dan pinggang lebih besar. Biasanya serangga ini akan bermunculan pada senja dan malam hari, kebiasaannya adalah mengerubuti lampu di dalam rumah dan tempat-tempat yang terang. 
Masyarakat Dayak Simpakng beranggapan dan meyakini bahwa nakne merupakan hewan petanda mudiknya ikan kehulu sungai, bertelur dan menandakan ikan keluar dari sarangnya serta mudah untuk ditangkap. Pada masa inilah masyarakat Dayak Simpakng berbondongbondong ke sungai, mencari ikan dan memasang perangkap, jika beruntung tangkapan ikan yang didapatpun cukup banyak dan dapat disedekahkan kepada para keluarga.

\section{Ciri-ciri Hewan yang Dijadikan Sebagai Mistis}

Ciri-ciri hewan yang dimanfaatkan oleh masyarakat Dayak Simpakng sebagai mistis yang paling banyak adalah pada suara yaitu sebanyak 44\% atau 11 dari 23 jenis hewan yang dipercaya sebagai mistis. Hewan-hewan tersebut antara lain owa kelampiau, bubut alang-alang, gagak bangai, burung hantu, kucing, macan dahan, burung kuang kuit, terenggiling, kacer, ayam, cicak dan tonggeret. Hewan mistis memberi padah atau peringatan dengan masuk kedalam rumah (seluruh bagian tubuh) sebanyak $36 \%$ atau 9 dari 23 jenis hewan yang dipercaya sebagai mistis. Hewan-hewan tersebut antara lain pipit, puyuh sengayan, kareo padi, murai batu, burung kedasih, perkutut, pijantung kecil, kunang-kunang dan anai-anai. Hewan mistis memberi padah atau peringatan saat terbang melintasi kampung atau pemukiman warga sebanyak (seluruh bagian tubuh) $16 \%$ atau 4 dari 23 jenis hewan yaitu Bubut alang-alang, gagak bangai, tali mayat dan kacer.

Pemanfaatan organ tubuh hewan yang diangap mistis sebanyak 4\% yaitu kaki dari burung sempidan dipercaya oleh masyarakat Dayak Simpakng dapat mengusir makluk halus yang mengganggu anak-anak atau bayi pada saat tidur disore hari. Jumlah keseluruhan pemanfaatan satwa sebagai mistis sebanyak 25. Berikut ini tersaji diagram pemanfaatan hewan sebagai mistis oleh Masyarakat Dayak Simpakng.

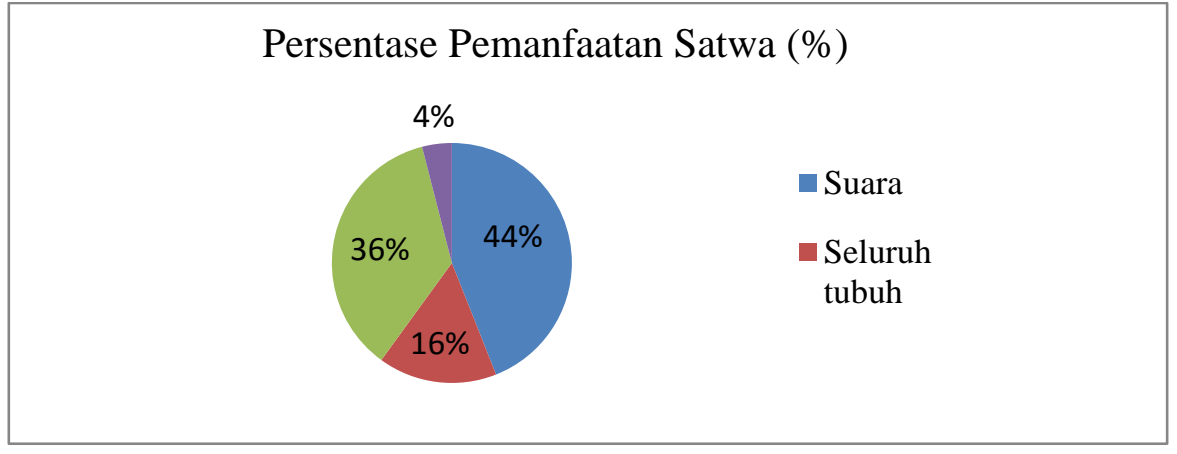

Gambar 2. Diagram Pemanfaatan Hewan sebagai Mistis oleh Masyarakat Dayak Simpakng di Desa Semandang Kanan Kecamatan Simpang Dua Kabupaten Ketapang (Animal Utilization Diagram as a Myth by the Simpakng Dayak Community in Semandang Kanan Village Simpang Dua District Ketapang Regency) 


\section{Kesimpulan}

Masyarakat Suku Dayak Simpakng merupakan suku Dayak yang masih menjaga budaya leluhur secara turun temurun. Salah satu budaya mereka yaitu masih memanfaatan hewan liar yang ada disekitarnya serta masyarakatnya masih menjalankan tradisi adat dengan menggunakan hewan liar sebagai mistis atau pertanda, sedikitnya ada 23 jenis satwa yang digunakan sebagai mistis oleh masyarakat. Ciri-ciri hewan yang dimanfaatakan sebagai pertanda yaitu suara, organ tubuh, hewan yang dengan tiba-tiba masuk ke dalam rumah, dan hewan yang melintasi kampung atau pemukiman warga.

\section{Saran}

Perlunya dilakukan penelitian lebih lanjut mengenai hewan-hewan yang dimanfaatkan sebagai pengobatan, budaya dan konsumsi agar memperoleh informasi yang lebih jelas tentang etnozoologi Dayak Simpakng.

\section{DAFTAR PUSTAKA}

Augristina M. 2014. Makna Tradisi "Dekahan" Bagi Masyarakat Desa Pakel. Fakultas Keguruan dan Ilmu Pendidikan Universitas Sebelas Maret. Jurnal Penelitian FKIP UNS Vol. 4 (1): 14

Eprilurahman RIK, Kusmana dan SD. Yudha. 2012. Sekilas Etnozoologi Masyarakat Dayak Di Kalimantan. Yogyakarta: Fakultas Biologi Universitas Gadjah Mada.

Kumparan. 2017. Mistis dan Magisnya Suku Dayak di Kalimantan. https://kumparan.com/mistis-danmagisnya-suku-dayak-di- kalimantan.html. Diakses pada tanggal 29 November 2019.

Li TM. (1999) Transforming the Indonesian uplands marginalit, power and production. Singapore: Ed. Harwood Pantheon Books.

Manshur A, Yunus MA, Saputra, Mansyur FI. 2008. Owa Kelawat (Hylobates Muelleri) Sebagai Obyek Wisata Primata Di Taman Nasional Bukit Baka-Bukit Raya. https://docplayer.info/64914340Owa-kelawat-hylobates-muellerisebagai-obyek-wisata-primata-ditaman-nasional-bukit-baka-bukitraya.html. [28 Nov 2019].

National Geographic Indonesia. 2018. Kunang-kunang (Photuris lucicrescens). http:// nationalgeographic.grid.id/animal s.html. Diakses pada tanggal 29 November 2019.

Parthami PW. 2009. Konstruksi Identitas Jender. Skripsi. Jakarta: Fakultas Psikologi Universitas Indonesia.

Payne J, Francis CM, Phillips K dan Kartikasari SN. 2000. Panduan Lapangan Mamalia di Kalimantan, Sabah, Serawak, dan Brunei Darussalam. Kinabalu: The Sabah Society.

Poerwandari EK. 1998. Metode Penelitian Sosial.Universitas Terbuka: Jakarta.

Roach J. 2005. Vanishing Borneo Pheasants Look Great but Won't Mate National GeogrpahicNews.(Online)https://i d.wikipedia.org/wiki/Sempidan_k alimantan\#cite_ref-1. Diakses pada tanggal 28 November 2019. 
Sanderson J, Khan JA, Grassman L, Mallon DP. 2008. "Neofelis nebulosa". IUCN Red List of Threatened Species. International Union for Conservation of Nature.
Yogi Y. 2017. Etnozoologi Masyarakat Dayak Simpakng di Desa Mekaraya Kecamatan Simpang Dua Kabupaten Ketapang. Skripsi. Pontianak: Fakultas Kehutanan Universitas Tanjungpura. 